\title{
Young and thriving is okay; young and not thriving is not
}

Timothy J. Pirolli, MD, and Robert D. B. Jaquiss, MD

\author{
From the Division of Pediatric Cardiothoracic Surgery, Department of Cardiovascular and Thoracic Surgery, \\ Children's Medical Center and University of Texas Southwestern Medical Center, Dallas, Tex. \\ Disclosures: Authors have nothing to disclose with regard to commercial support. \\ Received for publication March 26, 2017; accepted for publication March 28, 2017; available ahead of print April \\ 20, 2017. \\ Address for reprints: Robert D. B. Jaquiss, MD, Division of Pediatric Cardiothoracic Surgery, 1935 Medical \\ District Drive, Suite B3409, Dallas, TX 75235 (E-mail: robert.jaquiss@utsouthwestern.edu). \\ J Thorac Cardiovasc Surg 2017;154:239-40 \\ $0022-5223 / \$ 36.00$ \\ Copyright (c) 2017 by The American Association for Thoracic Surgery \\ http://dx.doi.org/10.1016/j.jtcvs.2017.03.128
}

For children who have survived the Norwood procedure, the performance of the second stage of palliation, the superior cavopulmonary shunt (CPS), marks the conclusion of the so-called interstage period and converts the circulatory system from a parallel arrangement to the more efficient in-series scheme. The most important advantages of the CPS arrangement are a reduction in vulnerability to sudden death and an increased growth trajectory, suggesting that "earlier is better" is a reasonable approach to CPS timing. However, several important questions related to CPS timing remain unanswered: How young (small) is too young (small)? Are outcomes after nonelective CPS worse than after elective CPS? Are risk factors beyond age and size relevant for timing? The present report, ${ }^{1}$ a retrospective analysis of 297 patients undergoing post-Norwood CPS at a single center over 12 years, attempts to answer these and other questions.

Strengths of the study include the large size of the cohort, consistency of approach over the study period, length of follow-up, and superb completeness of follow-up (100\%). Barron and colleagues ${ }^{1}$ not only focused on intrinsic cardiac factors, such as ventricular function and atrioventricular valve regurgitation, but also analyzed the role of interstage interventions to optimize circulatory efficiency, the influence of indexed somatic growth of the patient, and whether the CPS procedure was elective (planned) or nonelective (unplanned).

Early mortality was low in the entire cohort and not different $(P=.07)$ between those with unplanned and planned CPS (5.3\% vs 1.3\%). However, long-term survival was significantly worse for the unplanned group (by log-rank analysis, $P=.035$ ), and unplanned surgery was a significant risk factor in a multivariable model of transplant-free survival overall (hazard ratio, 1.75). The finding of worse prognosis for nonelective patients was not surprising to Barron and colleagues ${ }^{1}$ and will not be to most experienced readers.

Less expected was the finding that patients requiring catheter interventions on the aorta or right ventricle-

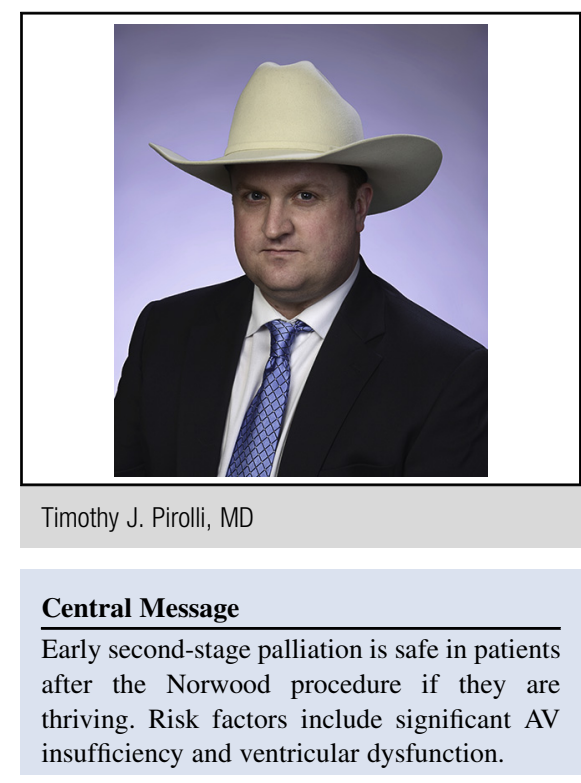

See Article page 228. pulmonary artery conduit were not at higher risk for early or late mortality. This is particularly encouraging because it suggests that intervention may have a favorable and durable effect on the natural history of patients with an initially imperfect hemodynamic result. In contrast, the findings that moderate or greater atrioventricular valve regurgitation, the need for atrioventricular valve repair, and more than moderate ventricular dysfunction, individually but most powerfully in combination, were risk factors for mortality are consistent with previous studies. $^{2}$ The impact of aortic valve (AV) pathology was substantial, and indeed the need for AV intervention was termed by the authors "...the strongest...risk factor for death or transplantation." 1 Barron and colleagues ${ }^{1}$ suggest that $\mathrm{AV}$ intervention is warranted in patients with regurgitation moderate or more, although other authors have suggested a less-aggressive approach may be reasonable.

The importance of age-indexed weight as a predictive factor of survival is another critical point and expands on prior data. ${ }^{4,5}$ This finding confirms the need for monitoring and optimizing nutrition to improve outcomes, and emphasizes the value of the home-monitoring programs, now standard at most institutions. ${ }^{6,7}$ Such programs may aid in preventing the occurrence of unplanned CPS by identifying modifiable risk factors 
that can be addressed by catheter-based (or nutritional) intervention before the planned CPS.

Last, the report provides valuable information about the interplay of age and outcome after CPS. Remarkably, Barron and colleagues ${ }^{1}$ found no worse outcomes for even the youngest quintile in their cohort, those aged 39 to 121 days. However, lest the overeager reader rush to schedule a CPS for a 6-week-old candidate, the authors strongly emphasize that age is not a risk factor for worse outcomes, but only if "somatic growth is normal." Young and skinny is not the same as young and robust in this cohort.

This report confirms that patients post-Norwood without failure to thrive, significant AV insufficiency, or ventricular dysfunction have better post-CPS survival than patients with any of those risk factors and suggests that low-risk patients do well with even very early CPS. Perhaps most important, the study is a superb example that useful and practical information can arise even from studies that are not prospective and randomized, as long as investigators are consistent, careful, and complete in their analysis.

\section{References}

1. Barron DJ, Ul Haq I, Crucean A, Stickley J, Botha P, Khan N, et al. The importance of age and weight on cavopulmonary shunt (stage II) outcomes after the Norwood procedure: Planned versus unplanned surgery. J Thorac Cardiovasc Surg. 2017; 154:228-38.

2. Chetan D, Kotani Y, Jacques F, Poynter JA, Benson LN, Lee K-J, et al. Surgical palliation strategy does not affect interstage ventricular dysfunction or atrioventricular valve regurgitation in children with hypoplastic left heart syndrome and variants. Circulation. 2013;128(Suppl 1):S205-12.

3. Mahle WT, Cohen MS, Spray TL, Rychik J. Atrioventricular valve regurgitation in patients with single ventricle: impact of the bidirectional cavopulmonary anastomosis. Ann Thorac Surg. 2001;72:831-5.

4. Srinivasan C, Jaquiss RD, Morrow WR, Frazier EA, Martin D, Imamura M, et al. Impact of staged palliation on somatic growth in patients with hypoplastic left heart syndrome. Congenit Heart Dis. 2010;5:546-51.

5. Anderson JB, Beekman RH, Border WL, Kalkwarf HJ, Khoury PR, Uzark K, et al. Lower weight-for age z-score adversely affects hospital length of stay after the bidirectional Glenn procedure in 100 infants with single ventricle. J Thorac Cardiovasc Surg. 2009;138:397-401.

6. Hansen JH, Furck AK, Petko C, Buchholz-Berdau R, Voges I, Scheewe J, et al. Use of surveillance criteria reduces interstage mortality after the Norwood operation for hypoplastic left heart syndrome. Eur J Cardiothorac Surg. 2012; 41:1013-8.

7. Dobrolet NC, Nieves JA, Welch EM, Khan D, Rossi AF, Burke RP, et al. New approach to interstage care for palliated high-risk patients with congenital heart disease. J Thorac Cardiovasc Surg. 2011;142:855-60. 